Article

\title{
Anti-Inflammatory Activities of the Ethanol Extract of Prasiola japonica, an Edible Freshwater Green Algae, and Its Various Solvent Fractions in LPS-Induced Macrophages and Carrageenan-Induced Paw Edema via the AP-1 Pathway
}

\author{
Laily Rahmawati ${ }^{1,+} \mathbb{D}^{\mathbb{D}}$, Sang Hee Park ${ }^{2,+} \mathbb{D}^{D}$, Dong Seon Kim ${ }^{1,+}$, Hwa Pyoung Lee ${ }^{1}$, Nur Aziz ${ }^{1} \mathbb{D}_{\text {, }}$ \\ Chae Young Lee ${ }^{1}\left(\mathbb{D}\right.$, , Seung A Kim ${ }^{1}$, Seok Gu Jang ${ }^{3}$, Dong Sam Kim ${ }^{3, *}$ and Jae Youl Cho ${ }^{1, *(D)}$
}

check for updates

Citation: Rahmawati, L.; Park, S.H.; Kim, D.S.; Lee, H.P.; Aziz, N.; Lee, C.Y.; Kim, S.A.; Jang, S.G.; Kim, D.S.; Cho, J.Y. Anti-Inflammatory

Activities of the Ethanol Extract of Prasiola japonica, an Edible Freshwater Green Algae, and Its Various Solvent Fractions in LPS-Induced

Macrophages and

Carrageenan-Induced Paw Edema via the AP-1 Pathway. Molecules 2022, 27, 194. https://doi.org/10.3390/ molecules27010194

Academic Editor: Vaclav Vetvicka

Received: 5 November 2021

Accepted: 26 December 2021

Published: 29 December 2021

Publisher's Note: MDPI stays neutral with regard to jurisdictional claims in published maps and institutional affiliations.

Copyright: (C) 2021 by the authors. Licensee MDPI, Basel, Switzerland. This article is an open access article distributed under the terms and conditions of the Creative Commons Attribution (CC BY) license (https:// creativecommons.org/licenses/by/ $4.0 /)$
1 Department of Integrative Biotechnology, Sungkyunkwan University, Suwon 16419, Korea; lyrahma0106@g.skku.edu (L.R.); wetdry20@hanmail.com (D.S.K.); leehwapyoung57@gmail.com (H.P.L.); nuraziz@skku.edu (N.A.); chaeyoung2@g.skku.edu (C.Y.L.); seung-a26@naver.com (S.A.K.)

2 Department of Biocosmetics, Sungkyunkwan University, Suwon 16419, Korea; 84701@naver.com

3 Research and Business Foundation, Sungkyunkwan University, Suwon 16419, Korea; jangsg69@korea.kr

* $\quad$ Correspondence: prasiola@korea.co.kr (D.S.K.); jaecho@skku.edu (J.Y.C.); Tel.: +82-33-570-4427 (D.S.K.); +82-31-290-7876 (J.Y.C.)

+ These authors contributed equally to this work.

\begin{abstract}
Prasiola japonica possesses several biological activities. However, reports on the antiinflammatory activities and molecular mechanisms of its different solvent fractions remain limited. In this study, we investigated the potential anti-inflammatory activities of $P$. japonica ethanol extract (Pj$\mathrm{EE})$ and four solvent fractions of Pj-EE made with hexane (Pj-EE-HF), chloroform (Pj-EE-CF), butanol (Pj-EE-BF), or water (Pj-EE-WF) in both in vitro (LPS-induced macrophage-like RAW264.7 cells) and in vivo (carrageenan-induced acute paw edema mouse models) experiments. The most active solvent fraction was selected for further analysis. Various in vitro and in vivo assessments, including nitric oxide (NO), cytokines, luciferase assays, real-time polymerase chain reactions, and immunoblotting analyses were performed to evaluate the underlying mechanisms. In addition, the phytochemical constituents were characterized by Liquid chromatography-tandem mass spectrometry. In in vitro studies, the highest inhibition of NO production was observed in Pj-EE-CF. Further examination revealed that Pj-EE-CF decreased the expression of inflammation-related cytokines in LPS-induced RAW264.7 cells and suppressed subsequent AP-1-luciferase activity by inhibition of phosphorylation events in the AP-1 signaling pathway. Pj-EE-CF treatment also demonstrated the strongest reduction in thickness and volume of carrageenan-induced paw edema, while Pj-EE-BF showed the lowest activity. Furthermore, Pj-EE-CF also reduced gene expression and cytokines production in tissue lysates of carrageenan-induced paw edema. These findings support and validate the evidence that $\mathrm{Pj}-\mathrm{EE}$, and especially Pj-EE-CF, could be a good natural source for an anti-inflammatory agent that targets the AP1 pathway.
\end{abstract}

Keywords: Prasiola japonica; anti-inflammatory; paw edema; AP-1 pathway

\section{Introduction}

Inflammation is the protective response of the immune system against various pathogens and cellular danger signals, mediated primarily by immune cells such as macrophages. Acute inflammation is a process that involves the activation of complex enzymes, secretion of free radicals, and release of several inflammatory and pro-inflammatory mediators, which are commonly characterized by redness, swelling, pain, heat, and loss of tissue function [1-3]. The inflammatory response happens through the interaction of either pathogen-associated molecular patterns (PAMPs) or danger-associated molecular patterns with pattern recognition receptors $[1,4]$. For instance, engagement of PAMPs such as 
gram-negative bacteria-derived lipopolysaccharides (LPS) or carrageenan into toll-like receptor 4 will induce recruitment of adaptor proteins, MyD88 and TRIF, into the cytoplasm that eventually triggers inflammatory signaling cascades, including the activator protein-1 (AP-1) pathway [2,5,6]. The activation of the inflammatory signaling pathway is mediated by the initiation of signal transduction cascades activating a variety of intracellular signaling molecules. Three major mitogen-activated protein kinases (MAPKs), c-Jun N-terminal kinase (JNK), p38, and extracellular signal-regulated kinase (ERK), mediate nuclear translocation and activate transcription factors in the AP-1 pathway [3,7]. Activation of this transcription factor induces the expression of numerous inflammatory genes, such as inducible nitric oxide synthase (iNOS), cyclooxygenase-2 (COX-2), interleukin (IL)-6, IL-1 $\beta$, and tumor necrosis factor-alpha (TNF- $\alpha$ ), which will also stimulate matrix metalloproteinase (MMP) expression, subsequently releasing the production of the inflammatory mediator, nitric oxide (NO), and various cytokines [4,8-11]. Even though inflammation is a protective immune response, uncontrolled acute inflammation may become chronic, contributing to a variety of chronic inflammatory diseases. Several studies have provided evidence that inflammation is involved in the pathogenesis of many diseases including autoimmune diseases, cancer, and other life-threatening disorders [2,3,5,12]. As a result, a variety of efforts, including developing anti-inflammatory agents to regulate inflammatory responses and authenticating the agents to specifically target the molecular signaling, could potentially ameliorate several inflammatory diseases.

Some green algae (phylum Chlorophyta) are considered a representative natural source for pharmaceutical, nutraceutical, and cosmeceutical products $[13,14]$. Green algae, especially from the genus Prasiola, have a diverse distribution. At least 14 of 36 species are freshwater organisms, and other species grow in terrestrial habitats. Prasiola japonica belongs to the family Prasiolaceae and is found growing in freshwater ecosystems [15]. Prasiola japonica has been reported in east Asia and especially in Japan and in the Republic of Korea [16,17]. This alga possesses an assortment of components, including mannitol, loliolide, glucitol, alverine, diisopropylamine, and methyl pyrazine [18]. In recent years, the freshwater green algae $P$. japonica has been shown to possess medicinal benefits including antioxidant, antiapoptotic, anti-melanogenic, and anti-inflammatory effects. However, most of those studies were limited to identifying such effects of the crude ethanolic extract of $P$. japonica in the NF-KB pathway and mainly focused on the skin cell lines [13,18-20]. To the best of our knowledge, the present study is the first to describe the potential anti-inflammatory activities of $P$. japonica ethanol extract (Pj-EE) and four of its solvent fractions-hexane (Pj-EE-HF), chloroform (Pj-EE-CF), butanol (Pj-EE-BF), and water (Pj-EE-WF) — in in vitro (LPS-induced macrophage-like RAW264.7 cells) studies. The most active fraction, Pj-EE-CF, is selected to determine additional activities. In in vivo studies in carrageenan-induced acute paw edema mouse models, the molecular targets and phytochemical constituents of $\mathrm{Pj}$-EE-CF are also evaluated.

\section{Results}

\subsection{Effect of Pj-EE and Its Various Solvent Fractions on the NO Production of LPS-Induced Macrophages}

To initially determine whether Pj-EE and its four solvent fractions have anti-inflammatory potential, we tested the production level of an inflammatory mediator such as NO on LPSinduced macrophages with the same concentrations of Pj-EE and its fractions $(100 \mu \mathrm{g} / \mathrm{mL})$. As demonstrated in Figure 1a, LPS significantly increased $(p=0.0021)$ the secretion of NO in macrophage-like RAW264.7 cells. Pj-EE-CF $(100 \mu \mathrm{g} / \mathrm{mL})$ had the strongest effect $(p=0.0071)$ on the secretion of NO and up to $80 \%$ inhibition on LPS-induced RAW264.7 cells. In contrast, treatment with $\mathrm{Pj}$-EE, Pj-EE-HF, Pj-EE-BF, and Pj-EE-WF did not exert significant inhibition. Furthermore, using a conventional 3-(4,5-dimethylthiazol,2-yl)-2,5-diphenyltetrazolium bromide (MTT) assay, we checked the cell viability on macrophage-like RAW264.7 cells upon treatment with $\mathrm{Pj}$-EE and the four solvent fractions. However, treatment with $\mathrm{Pj}$-EE$\mathrm{CF}$ at a concentration that significantly reduced $\mathrm{NO}$ production indicated an interference of cell viability by up to $25 \%$ (Figure $1 \mathrm{~b}$ ). Consequently, we sought to identify the potential 
effect of Pj-EE-CF at a lower concentration than $100 \mu \mathrm{g} / \mathrm{mL}$ that did not exert cytotoxicity. As shown in Figure 1c, treatment with Pj-EE-CF did not suppress cell viability at concentrations up to $50 \mu \mathrm{g} / \mathrm{mL}$. Conversely, 100 and $200 \mu \mathrm{g} / \mathrm{mL}$ of Pj-EE-CF treatment significantly decreased cell viability by up to $80 \%$. Furthermore, to check whether a concentration lower than $100 \mathrm{\mu g} / \mathrm{mL}$ of Pj-EE-CF also has anti-inflammatory activity, we re-evaluated the secretion of NO on LPS-induced in RAW264.7 cells. The result showed that pretreatment with Pj-EE-CF concentration-dependently and significantly suppressed secretion of $\mathrm{NO}$ production at concentration of 25 and $50 \mu \mathrm{g} / \mathrm{mL}(p=0.0134$ and $p=0.0044$, respectively) (Figure 1d). These results suggested that treatment with Pj-EE-CF at concentrations up to $50 \mu \mathrm{g} / \mathrm{mL}$ affects NO production and has anti-inflammatory potential that is not due to cell death. Therefore, Pj-EE-CF was chosen to complete further experiments. Ultimately, we performed LC/MS-MS analyses to determine the phytochemical constituents of Pj-EE-CF, and we especially focused on parameter assays for flavonoids. Around 23 components from various flavonoid classes were observed, including the presence of maltol, at a retention time (RT) of 0.84 , bavachinin at an RT of 6.11, flavonol at an RT of 6.42, 3'-deoxysappanone $\mathrm{B}$ at an RT of 8.20, kushenol N and X, at RTs of 10.61 and 11.62, respectively, nobiletin at an RT of 12.64, and phellochinin A at an RT of 14.53, as shown in Figure 1e and Supplementary Table S1.

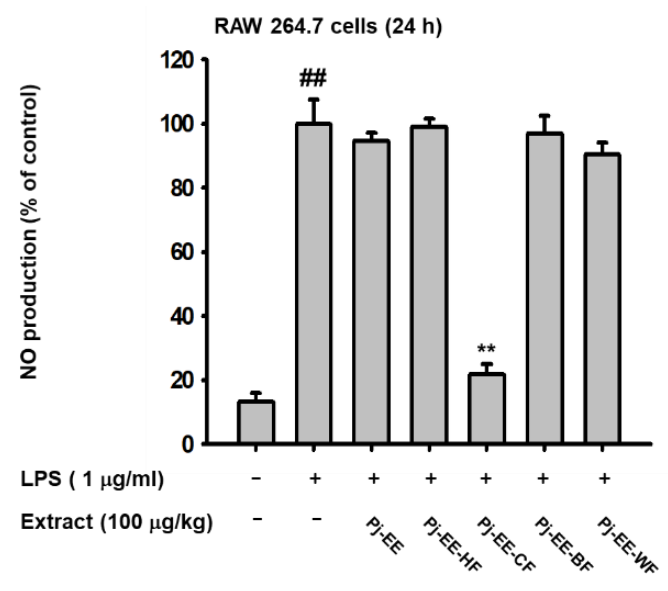

(a)

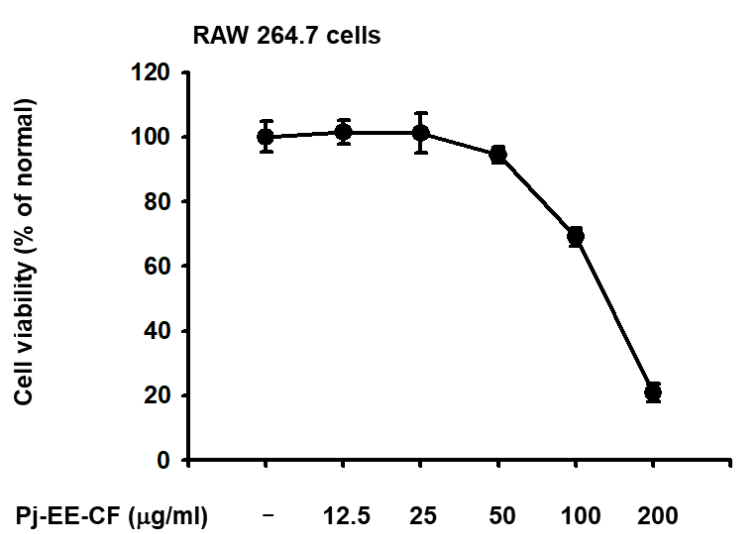

(c)

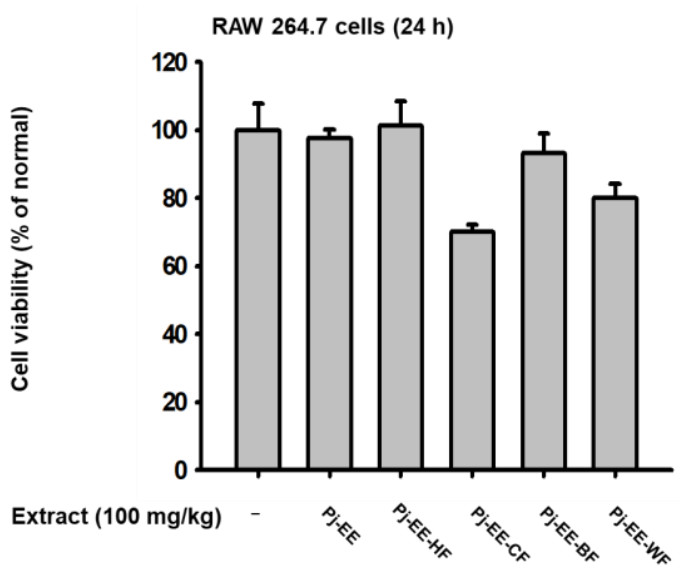

(b)

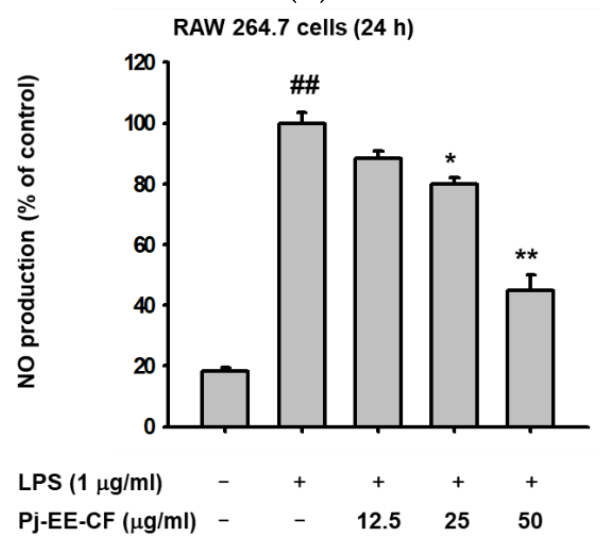

(d)

Figure 1. Cont. 




(e)

Figure 1. Effect of Pj-EE and its solvent fractions on the production of $\mathrm{NO}$, cell viability profile, and phytochemical constituents of Pj-EE-CF. (a,d) Supernatant NO levels on LPS $(1 \mu \mathrm{g} / \mathrm{mL})$-induced RAW264.7 cells pretreated with $100 \mu \mathrm{g} / \mathrm{mL}$ of Pj-EE, Pj-EE-HF, Pj-EE-CF, Pj-EE-BF, or Pj-EE-WF (a) and with the indicated concentrations of PJ-EE-CF (d) were analyzed using the Griess assay. $(\mathbf{b}, \mathbf{c})$ Cell viability of RAW264.7 cells upon treatment with Pj-EE, Pj-EE-HF, Pj-EE-CF, Pj-EE-BF, or Pj-EE-WF (b) and PJ-EE-CF (c) at the same concentration on NO assay were analyzed using an MTT assay. (e) The phytochemical screening performed on Pj-EE-CF using LC/MS-MS chromatogram. Results (a-d) are expressed as mean \pm standard deviation. ${ }^{\# \#} p<0.01$ compared to normal group (no treatment), and ${ }^{*} p<0.05,{ }^{* *} p<0.01$ compared to control group (LPS alone) by one-way ANOVA.

\subsection{Effects of Pj-EE-CF on the Expression of Pro-Inflammatory Genes on LPS-Induced Macrophages}

We initially determined that Pj-EE-CF treatment on LPS-stimulated RAW264.7 cells can reduce inflammatory mediators such as NO. To further our study, we examined whether Pj-EE-CF also can regulate the expression of pro-inflammatory mediators at the transcriptional level. Using quantitative real-time polymerase chain reaction (qPCR), we assessed the mRNA expression of iNOS, COX-2, and other pro-inflammatory cytokines, such as TNF- $\alpha$, IL-1 $\beta$, IL-6, and IL-10. As shown in Figure 2, LPS alone upregulated the level of inflammatory genes $(p<0.001)$, and treatment with Pj-EE-CF downregulated the expression of pro-inflammatory genes. In line with the result of the NO assay, LPSstimulated RAW264.7 cells pretreated with Pj-EE-CF at concentrations of 25 and $50 \mu \mathrm{g} / \mathrm{mL}$ significantly inhibited in a concentration-dependent manner the mRNA levels of iNOS ( $p=0.0094$ and $p=0.0068$, respectively), the enzyme that is responsible for catalyzing the secretion of NO (Figure 2a). Moreover, other pro-inflammatory and cytokine genes, such as COX-2, TNF- $\alpha$, IL-1 $\beta$, IL-6, and IL-10 (Figure $2 b-f$, respectively), also were shown to be reduced in a concentration-dependent manner by pretreatment with $\mathrm{Pj}-\mathrm{EE}-\mathrm{CF}$, for concentrations of up to $50 \mu \mathrm{g} / \mathrm{mL}(p=0.0026, p=0.0211, p=0.0005, p=0.0022$, and $p=0.0009$, respectively). 


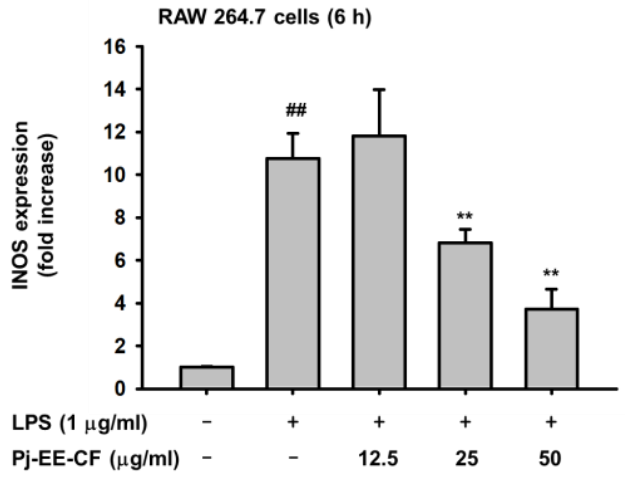

(a)

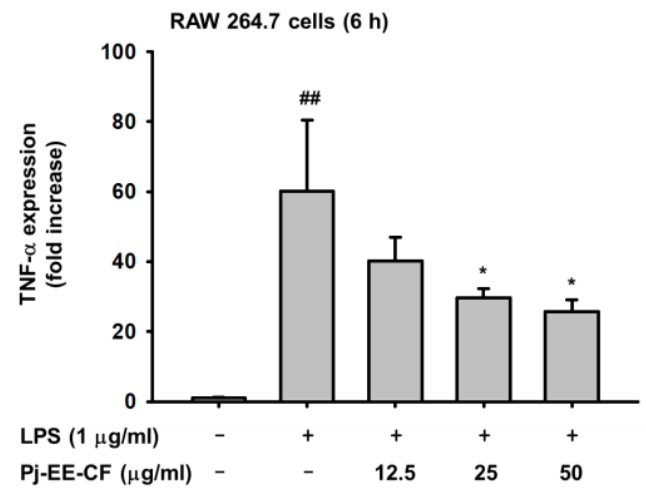

(c)

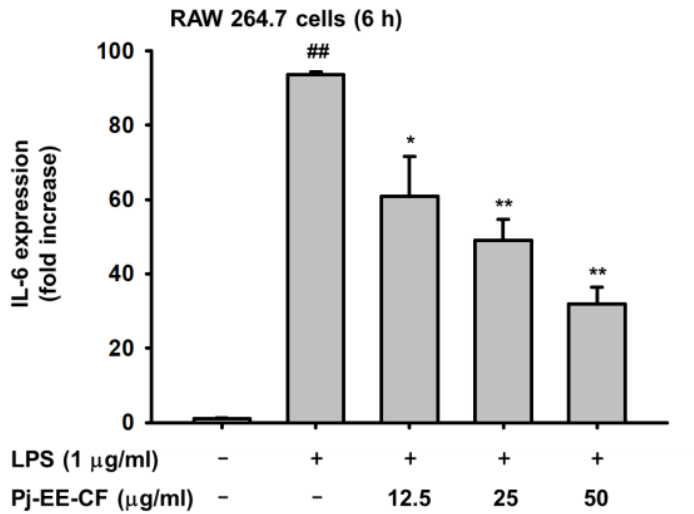

(e)

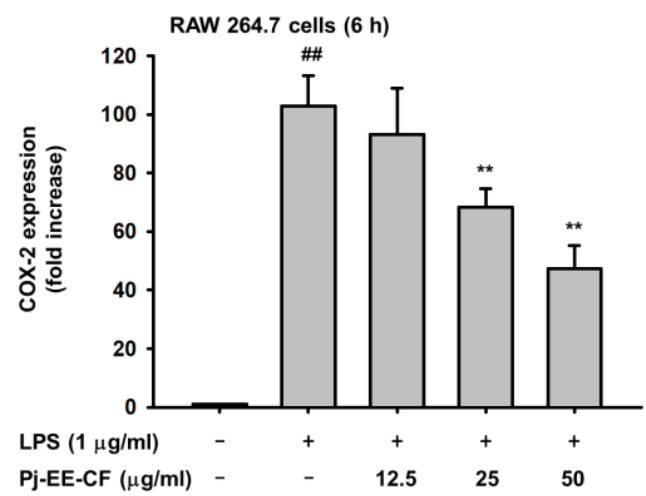

(b)

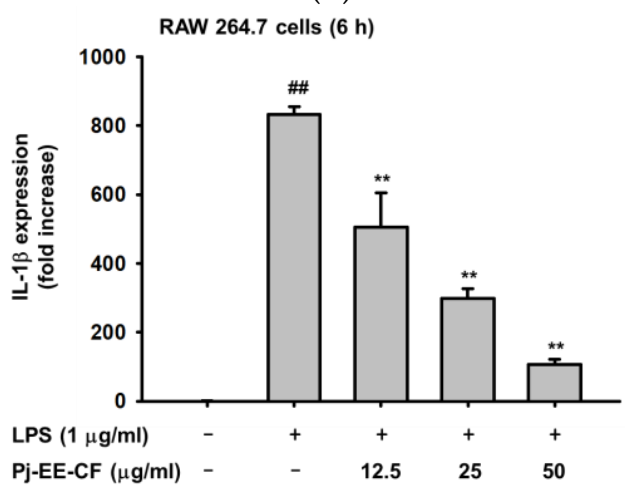

(d)

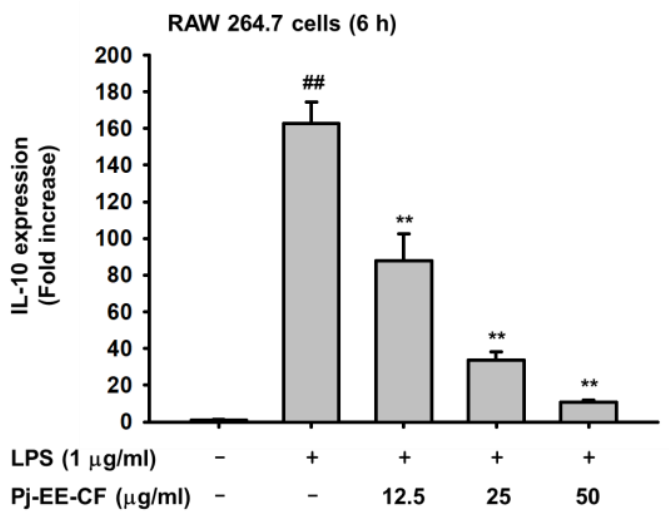

(f)

Figure 2. Effect of Pj-EE-CF on the expression of pro-inflammatory genes. The mRNA levels of iNOS (a), COX-2 (b), TNF- $\alpha$ (c), IL-1 $\beta$ (d), IL-6 (e), and IL-10 (f) were evaluated by qPCR on LPS-stimulated RAW264.7 cells. Results are expressed as mean \pm standard deviation. \#\# $p<0.01$ compared to normal group, and ${ }^{*} p<0.05$ and ${ }^{* *} p<0.01$ compared to control group (LPS alone). The $p$ value was calculated using Bio-Rad CFX software.

\subsection{Effects of Pj-EE-CF on the Transcriptional Activation of AP-1 Signaling and the Upstream} Signaling Molecules of AP-1 Activation

Next, due to the significant inhibitory effect of pro-inflammatory gene regulation, which was analyzed by qPCR, we sought to explore the transcriptional level using another assessment, the luciferase assay, using HEK293 cells co-transfected with either TRIF- or MyD88-mediated AP-1 activity. The results indicated that LPS alone significantly enhanced TRIF- or MyD88-mediated AP-1 activity ( $p=0.0078$ and $p=0.0035$, respectively). However, treatment with up to $50 \mu \mathrm{g} / \mathrm{mL}$ of Pj-EE-CF concentration-dependently suppressed AP-1 luciferase activity induced by either TRIF or MyD88 (Figure 3a,b). In addition, we also 
examined the protein level of AP-1 subunit activation, specifically the phosphorylation of c-Jun and c-Fos, from whole lysates in LPS-induced RAW264.7 cells at different concentrations $(12.5,25$, and $50 \mu \mathrm{g} / \mathrm{mL})$. This finding showed that Pj-EE-CF decreased the level of p-c-Jun and p-c-Fos at all indicated concentrations (Figure 2c), which indicated that $\mathrm{Pj}$-EE-CF could regulate the activity of AP-1 by inhibiting the dimerization of AP-1 via the reduction of activation of c-Jun and c-Fos. Afterward, to determine the target molecules of $\mathrm{Pj}$-EE in the AP-1 pathway, we identified the effect of Pj-EE-CF at different concentrations in the upstream signaling molecules of AP-1 activation by an immunoblot analysis. MAPKs activation was generated by LPS-induced RAW264.7 cells. Among the MAPKs, the phosphorylation levels of ERK and of p38 were clearly decreased in the presence of $\mathrm{Pj}$-EE-CF treatments at 25 and $50 \mu \mathrm{g} / \mathrm{mL}$. However, the phosphorylation levels of JNK were not affected, despite the Pj-EE-CF treatment (Figure 2d). Taken together, these results suggested that Pj-EE-CF exerts anti-inflammatory responses through suppression of ERK and $\mathrm{p} 38$ in the AP-1 pathway.

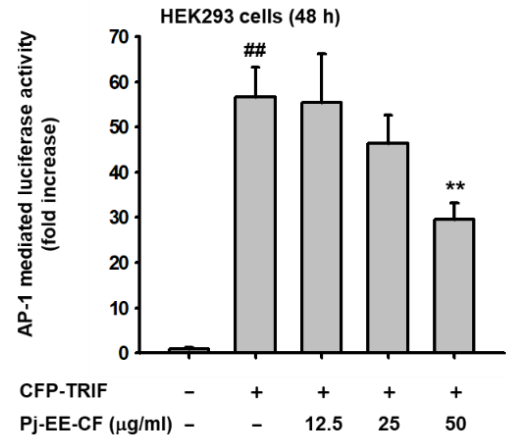

(a)

RAW264.7 cells

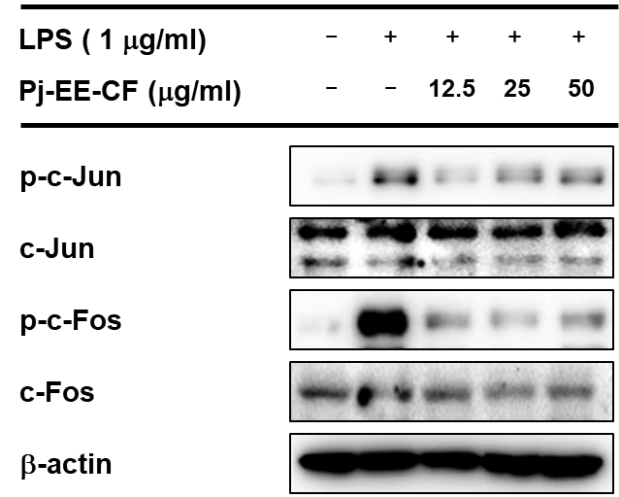

(c)

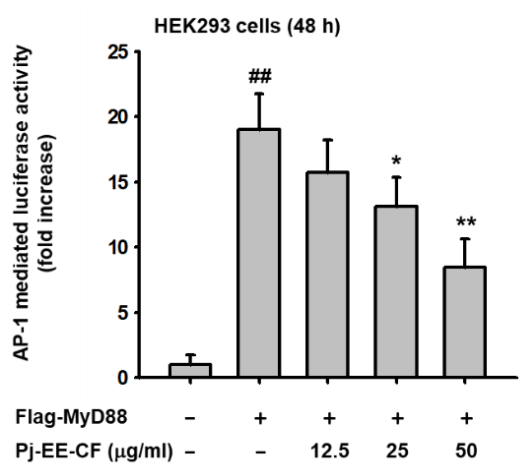

(b)

RAW264.7 cells

\begin{tabular}{|c|c|c|c|}
\hline $\begin{array}{l}\text { LPS }(1 \mu \mathrm{g} / \mathrm{ml}) \\
\text { Pj-EE-CF }(\mu \mathrm{g} / \mathrm{ml})\end{array}$ & $\begin{array}{llc}- & + & + \\
- & - & 12.5\end{array}$ & $\begin{array}{l}+ \\
25\end{array}$ & $\begin{array}{l}+ \\
50\end{array}$ \\
\hline p-ERK & - & $=$ & 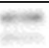 \\
\hline ERK & & & \\
\hline p-JNK & 50 & - & - \\
\hline JNK & - & & $=$ \\
\hline$p-p-38$ & & & \\
\hline p-38 & & & \\
\hline$\beta$-actin & & & D \\
\hline
\end{tabular}

(d)

Figure 3. Effect of Pj-EE-CF on the transcriptional activation of AP-1 signaling and the upstream signaling molecules of AP-1 activation. (a,b) HEK293 cells were co-transfected with AP-1-Luc and $\beta$-gal $(0.8 \mu \mathrm{g})$, as well as TRIF and MyD88 for $48 \mathrm{~h}$ in the presence or absence of Pj-EE-CF $(12.5,25$, and $50 \mu \mathrm{g} / \mathrm{mL}$ ), which were then examined using a luminometer. Results are expressed as mean \pm standard deviation $(n=4) .{ }^{\# \#} p<0.01$ compared to normal group, ${ }^{*} p<0.05$ and ${ }^{* *} p<0.01$ compared to control group (LPS alone) by one-way ANOVA. (c) The phospho- and total forms of AP-1 subunits, c-Jun and c-Fos, from whole-cell lysates from LPS-treated RAW264.7 cells in the presence or absence of Pj-EE-CF $(12.5,25$, and $50 \mu \mathrm{g} / \mathrm{mL})$ were determined by immunoblot analysis. (d) RAW264.7 cells were pretreated with $\mathrm{Pj}$-EE-CF $(12.5,25$, and $50 \mu \mathrm{g} / \mathrm{mL})$ for $30 \mathrm{~min}$, followed by the presence or absence of LPS. The phosphorylated and total protein levels of ERK, JNK, and p38 were assessed by immunoblot analysis. $\beta$-actin was utilized as a control protein. 


\subsection{Effects of Pj-EE and Its Solvent Fractions on a Carrageenan-Induced Acute Paw Edema Model}

To determine the anti-inflammatory efficacy of Pj-EE and its solvent fractions in vivo, carrageenan-induced acute paw edema mouse models were used. Inflammation in both hind paws of each mouse was triggered by intraplantar injection of $1 \%$ newly prepared solution of carrageenan in PBS after pretreatment with $100 \mathrm{mg} / \mathrm{kg} \mathrm{Pj-EE} \mathrm{and} \mathrm{the} \mathrm{four}$ different solvent fractions once a day for 10 days, as illustrated in Figure $4 \mathrm{a}$. As expected, carrageenan-induced paw edema showed prominent inflammatory symptoms, such as redness and swelling of the paws (Figure $4 \mathrm{a}$ ). In contrast, $100 \mathrm{mg} / \mathrm{kg}$ of Pj-EE and its solvent fractions decreased the symptoms compared to the control group (carrageenan alone). In addition, we quantitatively measured the weight, thickness, and volume (Figure $4 b-d)$ of each mouse paw to compare the severity of edema in each group. The water fraction following treatment with $\mathrm{Pj}$-EE and $\mathrm{Pj}$-EE-CF showed a significant reduction in paw weight compared to the control group ( $p=0.0098, p=0.0477$, and $p=0.0354$, respectively). However, $\mathrm{Pj}$-EE-CF had the lowest measurement both of thickness and volume compared to $100 \mathrm{mg} / \mathrm{kg}$ of $\mathrm{Pj}$-EE or the other solvent fraction groups, which suggested that it had more potent inhibitory effects, followed by Pj-EE, Pj-EE-HF, and Pj-EE-WF. Additionally, Pj-EE-BF did not show inhibitory symptoms on the carrageenan-induced paw edema mouse model.

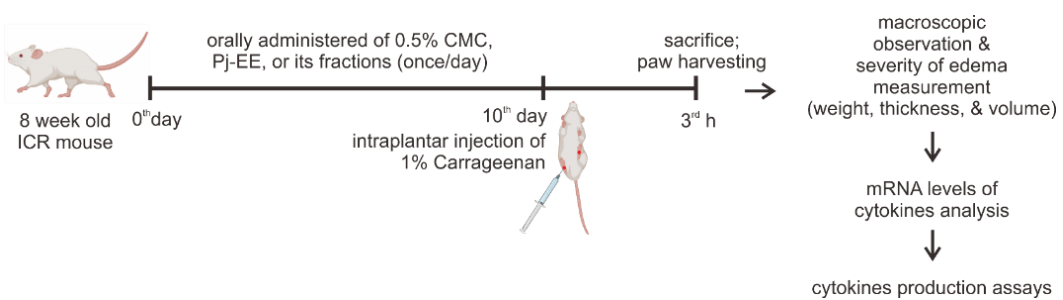

(a)



(b)

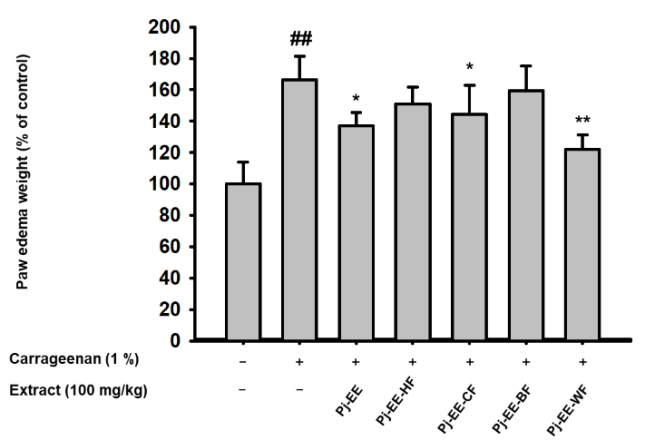

(c)

Figure 4. Cont. 


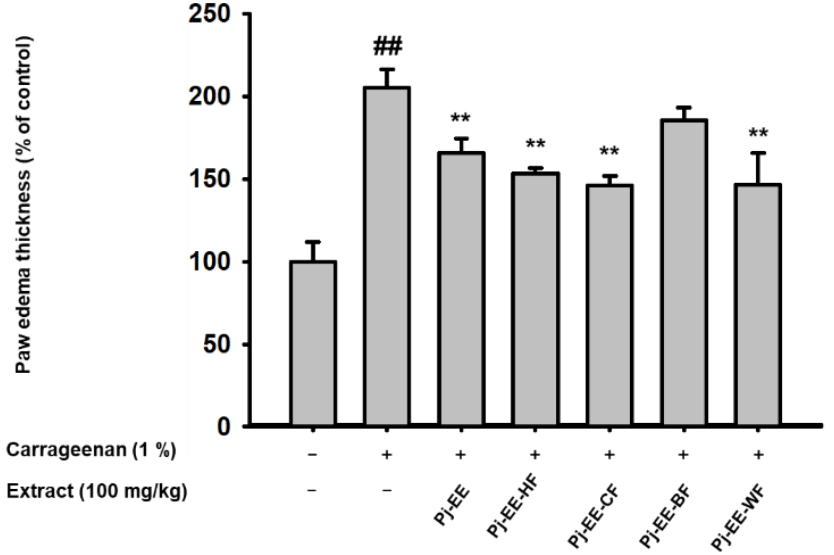

(d)

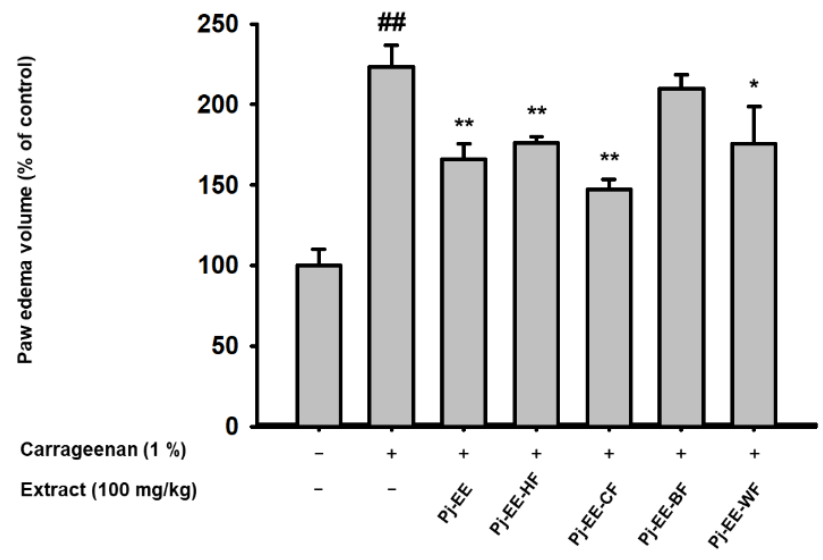

(e)

Figure 4. Effects of Pj-EE and four different solvent fractions on the carrageenan-induced acute paw edema mouse model. (a) Schematic of carrageenan-induced acute paw edema experiment. The ICR mice were orally treated with $100 \mu \mathrm{L}$ of different solutions based on different groups for 10 days: a normal group $(0.5 \%$ carboxymethylcellulose $(\mathrm{CMC}))$ or carrageenan group as a control group $(0.5 \%$ $\mathrm{CMC}$ ), treatment groups (100 mg/kg Pj-EE, Pj-EE-HF, Pj-EE-CF, Pj-EE-BF, or Pj-EE-WF). Acute paw edema was triggered by an intraplantar injection of $1 \%$ carrageenan $(100 \mu \mathrm{L} /$ mouse $)$ and mice were sacrificed after $3 \mathrm{~h}$. (b) A representative photograph of paw inflammatory symptoms. (c-e) The severity of paw edema was evaluated by measuring the weight (c), thickness (d), and volume (e) of each paw of mouse. Results are expressed as mean \pm standard deviation $(n=12)$. ${ }^{\# \#} p<0.01$ compared to normal group, and ${ }^{*} p<0.05$ and ${ }^{* *} p<0.01$ compared to control group (carrageenan alone). The $p$-value was analyzed using one-way ANOVA.

\subsection{Effects of Pj-EE and Its Solvent Fractions on Pro-Inflammatory Genes and Cytokines Production in Carrageenan-Induced Acute Paw Edema Models}

To evaluate the effects of $\mathrm{Pj}-\mathrm{EE}$ and its solvent fractions at the molecular level, the level of inflammatory genes in the tissue lysate of paw samples was examined by qPCR (Figure 5a-g). In agreement with in vitro experiments, Pj-EE-CF possessed the highest inhibition of inflammatory genes, such as iNOS (Figure 5a), COX-2 (Figure 5b), and MMP-9 (Figure 5g), whereas Pj-EE-BF had the lowest, or barely any, activities. Additionally, for other pro-inflammatory genes such as TNF (Figure $5 c$ ), Pj-EE-HF showed more significantly reduced expression of TNF- $\alpha$, followed by Pj-EE and Pj-EE-CF. In addition, in terms of the expression of IL-6 (Figure 5d), IL-1 $\beta$ (Figure 5e and MMP-2 (Figure 5f), the crude $\mathrm{Pj}$-EE showed more prominent inhibition of the inflammatory genes, despite Pj-EE-CF still showing significant inhibition activities of these pro-inflammatory genes. To confirm that $\mathrm{Pj}$-EE and its solvent fractions effectively inhibited the secretion of various cytokines, we further examined the production of IL1- $\beta$, IL- 4 , and TNF- $\alpha$ using enzyme immunoassay (EIA). Carrageenan-induced paw edema significantly generated the production of these cytokines, but treatment with $100 \mathrm{mg} / \mathrm{kg}$ PJ-EE and its four solvent fractions showed a reduction of these enzymes, with Pj-EE-CF displaying the highest attenuation of IL1- $\beta$ (Figure 5h), IL-4 (Figure 5i), and TNF- $\alpha$ (Figure 5j) secretions. These data indicated that $\mathrm{Pj}$-EE alleviated the inflammatory symptoms on carrageenan-induced paw edema, and, notably, Pj-EE-CF conferred more potent inhibition of almost all the assessments. 


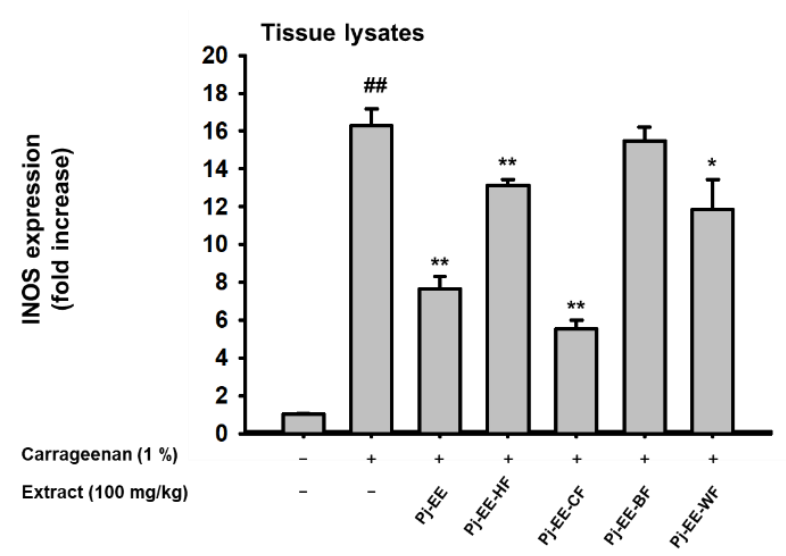

(a)

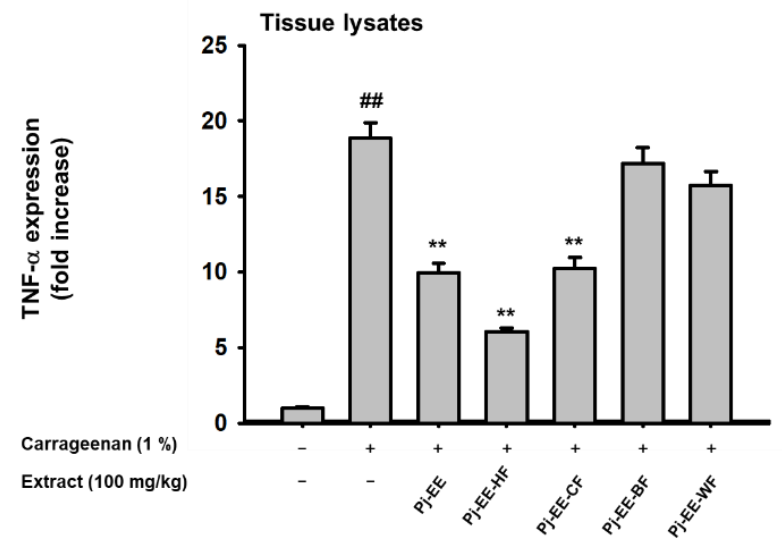

(c)

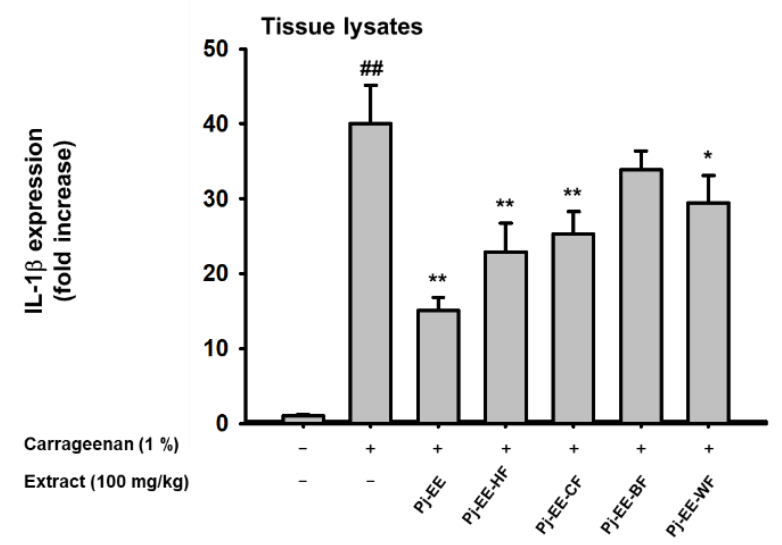

(e)

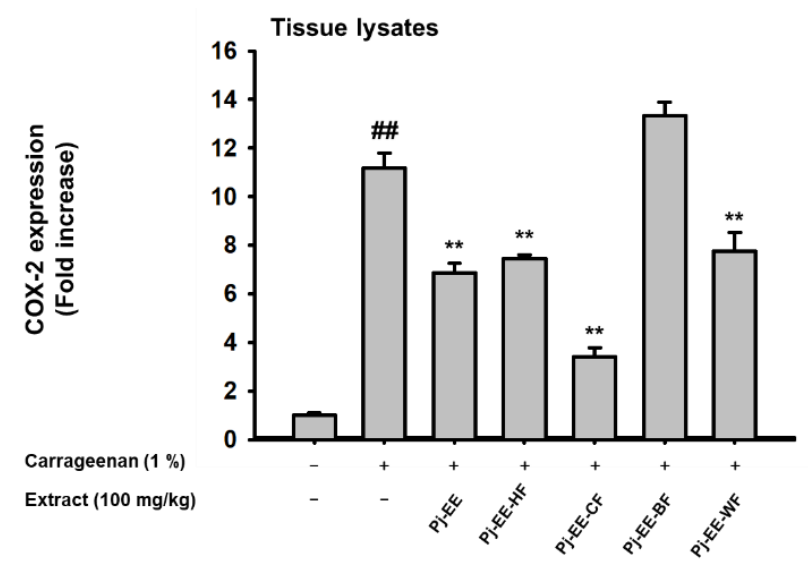

(b)

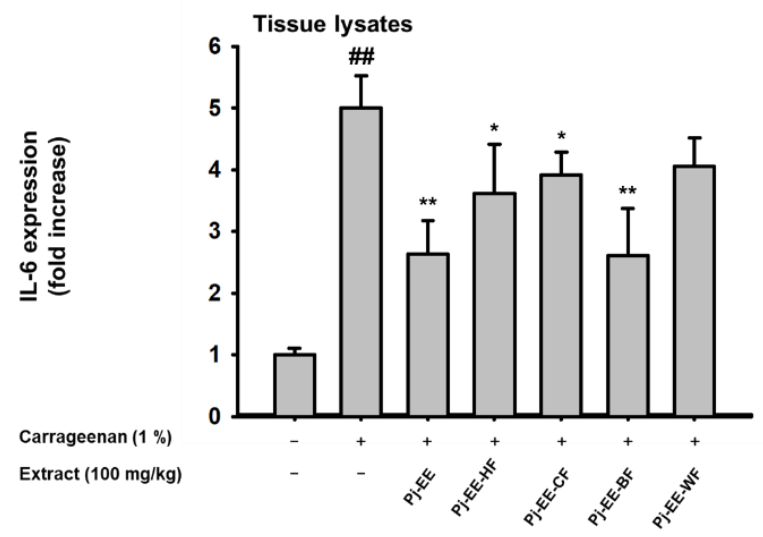

(d)

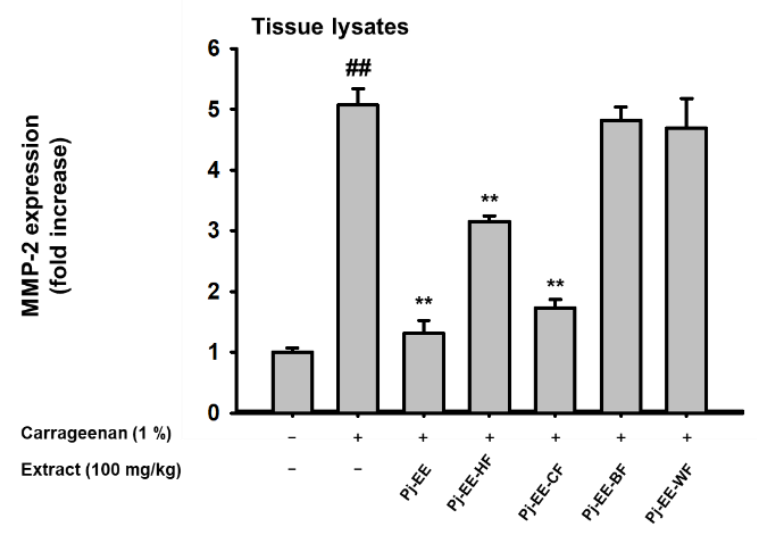

(f)

Figure 5. Cont. 


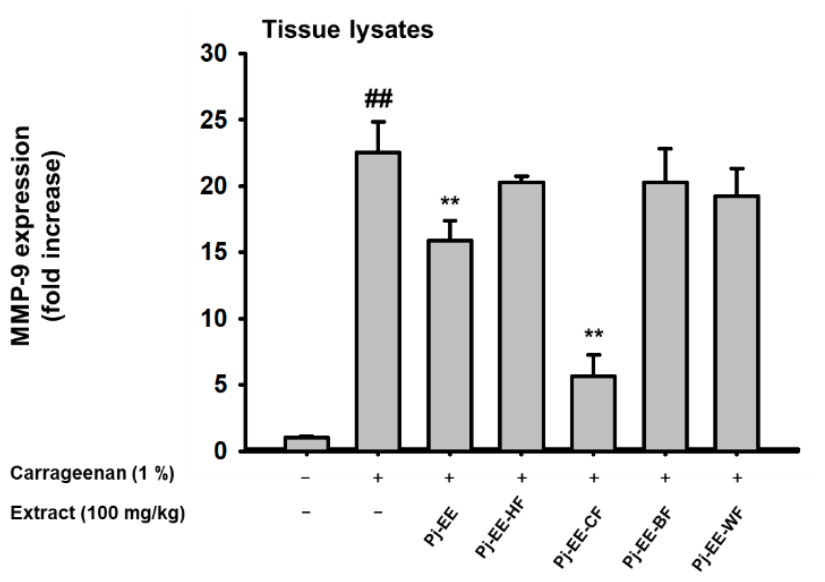

(g)



(i)

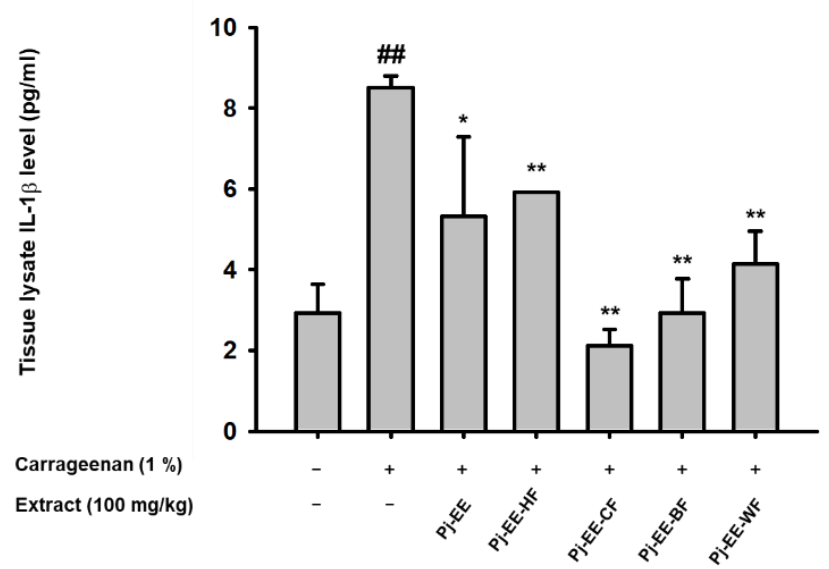

(h)
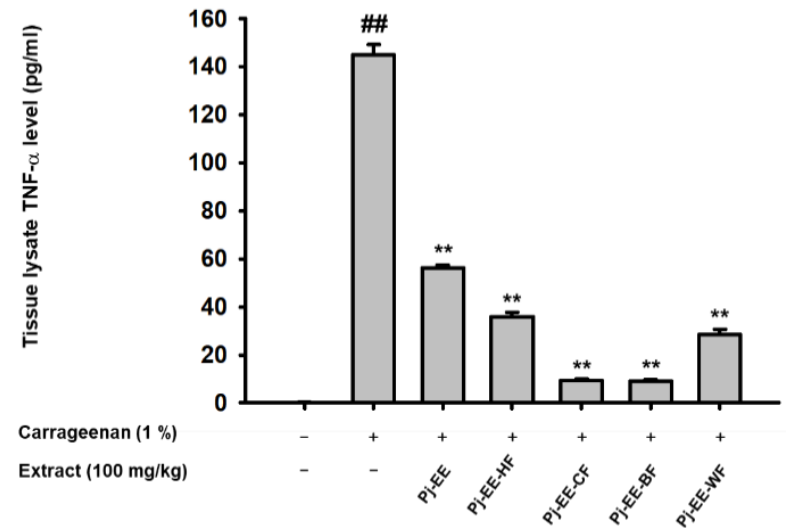

(j)

Figure 5. Effects of $\mathrm{Pj}-\mathrm{EE}$ and four solvent fractions $(\mathrm{HF}, \mathrm{CF}, \mathrm{BF}$, and $\mathrm{WF})$ on the pro-inflammatory genes and cytokines production in carrageenan-induced acute paw edema models. (a-g) The expression of inflammatory genes, including iNOS (a), COX-2 (b), TNF- $\alpha$ (c), IL-6 (d), IL-1 $\beta$ (e), MMP-2 (f), and MMP-9 (g) from paw lysates was measured by quantitative real-time PCR. (h-j) Supernatant IL-1 $\beta$ (h), IL-6 (i), and TNF- $\alpha$ (i) levels of tissue lysates on carrageenan-triggered paw edema were examined by EIA. All of the data are expressed as mean \pm standard deviation $(n=6)$. \#\# $p<0.01$ compared to the normal group, and ${ }^{*} p<0.05$ and ${ }^{* *} p<0.01$ compared to the control group (inducer alone) by one-way ANOVA.

\section{Discussion}

Medicinal plants with natural sources still offer promising options and are recognized as therapeutic agents. In addition, understanding the mechanisms of therapeutic action could lead to the discovery of new drugs from natural sources with reduced or no side effects [21-23]. The edible freshwater green algae, P. japonica, has been described to possess pharmacological benefits. Last year our research group reported that the ethanol extract of $P$. japonica exerts antiapoptotic, anti-melanogenic, and antioxidant effects on skin cell lines $[13,19]$. We also recently showed in vivo anti-inflammatory effects via the NF- $k B$ signaling pathway [20]. However, additional studies with respect to which solvent fractions have potential activity remained unclear. Therefore, in this study, using Pj-EE extract and four different solvent fractions, we aimed to investigate their anti-inflammatory potential against LPS-induced macrophage-like RAW264.7 cells and in carrageenan-induced paw edema mouse model, and then focused on which solvent fraction possessed more potent activities. We also determined the molecular mechanisms concerning the AP-1 pathway and the phytochemical constituents. 
In early characterizations of $\mathrm{NO}$, it was described as playing an important role in biological activities such as neurotransmission and immune defenses. However, research showed that while the production of NO is uncontrolled in the cells, it acts as one of the pro-inflammatory mediators and a key molecule during inflammatory responses [8]. In this study, NO production was stimulated by LPS, a major component of the outer membrane of gram-negative bacteria. Aggregation of the TLR4-adaptor proteins complex after binding LPS led to activation of multiple signaling molecules, and the subsequent production of pro-inflammatory cytokines and mediators [3,24]. Our first finding revealed that $\mathrm{Pj}$-EE-CF showed the highest inhibition of the secretion of NO (Figure 1). Based on this finding, we focused our investigations on its molecular mechanisms and also described its phytochemical constituents. Pj-EE-CF inhibited the expression of iNOS, an enzyme responsible for the mediation of NO production, in LPS-induced macrophages [8]. Other inflammatory cytokines and mediators that are broadly involved in inflammation via activation of its transcription, including COX-2, TNF- $\alpha$, interleukins, and MMPs, were also evaluated. The mRNA levels of those related genes, analyzed by qPCR, were determined to be downregulated in a concentration-dependent manner by Pj-EE-CF in vitro and in vivo (Figures 2 and 5), suggesting that $\mathrm{Pj}$-EE-CF could regulate inflammatory responses at the transcriptional level. Importantly, certain concentrations of Pj-EE-CF produced these effects without affecting cell viability, which suggested that the inhibitory effects were not due to non-specific toxicity.

In addition, to precisely identify the molecular target and mechanism of Pj-EE-CF, other experimental approaches, including luciferase assays and immunoblot analyses, were performed. The results of the luciferase reporter genes indicated that Pj-EE-CF regulates the mRNA level of cytokines by moderating the transcriptional activity of AP-1. Strengthening these findings, immunoblot analyses of the level of phosphorylation of AP-1 subunits, c-jun and c-Fos, revealed that Pj-EE-CF modulates the transcriptional activation of AP-1. Previous studies reported the essential role and mechanism of MAPKs in activating AP-1 pathways $[7,23,25]$. Consequently, we checked signaling molecules upstream of this AP-1 activation, and Pj-EE-CF specifically inhibited ERK and p38 activation. These results indicated how effective $\mathrm{Pj}$-EE-CF can be in attenuating anti-inflammatory responses, resulting in a reduction of ERK and p38 of the AP-1 pathway (Figure 3).

Several studies on the discovery and development of anti-inflammatory agents were based on the use of carrageenan-induced inflammation. Carrageenan-induced paw edema has been established as an experimental model of acute inflammatory diseases and has been widely used for studying novel analgesic and anti-inflammatory agents [6,20,26-28]. Carrageenan injection triggered an innate immune response characterized by edema, redness, and the continuing of neutrophil infiltration, and pro-inflammatory mediators and cytokines were involved in this process through TLR4-MyD88 or the TRIF complex [6]. Accordingly, to further evaluate and screen the anti-inflammatory efficacy of Pj-EE and its solvent fractions in vivo, we employed a carrageenan-induced paw edema mouse model. In agreement with other reported studies, intraplantar injection of $1 \%$ carrageenan into the hind paw led to inflammatory symptoms in the paws and generated the expression and production of pro-inflammatory cytokines. In addition, consistent with our in vitro results, $\mathrm{Pj}$-EE treatment, and especially PJ-EE-CF treatment, decreased inflammatory symptoms and exhibited protective effects for carrageenan-induced paw edema (Figure 4). Furthermore, because carrageenan has been reported to induce the production of pro-inflammatory cytokines, such as TNF- $\alpha$, IL- $1 \beta$, and IL-4, we also determined the production of these cytokines by enzyme immunoassay. The results indicated that $\mathrm{Pj}$-EE and its four solvent fractions decreased cytokines production, with $\mathrm{Pj}$-EE-CF showing the most significant inhibition (Figure 5). Taken together, the results supported that orally administered Pj-EE and its solvent fractions, especially $\mathrm{Pj}$-EE-CF, were able to alleviate inflammatory responses and could be clinically beneficial for treating inflammatory symptoms.

Phytochemical screening, especially pertaining to the flavonoids, for the possible presence of Pj-EE-CF was characterized using liquid chromatography-tandem mass spec- 
trometry (LC-MS/MS). Numerous flavonoid molecules have been described to obtain anti-inflammatory activity through various mechanisms, including inhibition of the expression of inflammation-related enzymes via suppression of transcription factors activation, including AP-1 [29-31]. Among the various flavonoid types that were present, maltol, bavachinin, nobiletin, flavonol, and $3^{\prime}$-deoxysappanone $B$ have been widely reported to possess bioactivity, such as anticancer, antimicrobial, and anti-inflammatory properties. The major flavonols, such as quercetin, kaempferol, isorhamnetin, and galangin, were found to exhibit anti-inflammatory activity [29,31]. Maltol exerts a significant liver protection effect, and possesses anti-inflammatory and antiapoptotic actions [32]. Some studies demonstrated that bavachinin, nobiletin, and 3'-deoxysappanone B regulate the production of several cytokines as well as inflammatory mediators in activated macrophages and various other cell types [32-38]. Consequently, we evaluated whether these components of Pj-EE-CF could be responsible for its anti-inflammatory effect.

\section{Materials and Methods}

\subsection{Materials}

Macrophage-like RAW264.7 cells (ATCC number TIB-71) and HEK293 cells (ATCC number CRL-1573) were obtained from the American Type Culture Collection (ATCC) (Rockville, MD, USA). TRIzol reagent was purchased from MRCgene (Cincinnati, OH, USA). Carrageenan, dimethyl sulfoxide (DMSO), carboxymethylcellulose (CMC), lipopolysaccharide (LPS, Escherichia coli 0111:B4), polyethylenimine (PEI), sodium dodecyl sulfate, and 3-(4,5-dimethylthiazol,2-yl)-2,5-diphenyltetrazolium bromide (MTT) were purchased from Sigma-Aldrich Co. (St. Louis, MO, USA). Fetal bovine serum was acquired from Biotechnics Research, Inc. (Irvine, CA, USA). RPMI 1640, DMEM, trypsin, PBS, and penicillin-streptomycin were obtained from HyClone (Logan, UT, USA). Primers used for qPCR were obtained from Macrogen Inc. (Seoul, Korea). Phospho-specific or total-protein antibodies against c-Fos, c-Jun, JNK, ERK, p38, and $\beta$-actin were purchased from Cell Signaling Technology (Beverly, MA, USA) and Santa Cruz Biotechnology (Santa Cruz, CA, USA). A CATX124 balance was purchased from CAS Co. (Yangju, Korea), a Mitutoyo thickness gauge 547 was received from Mitutoyo (Kanagawa, Japan), and a plethysmometer 37,140 was obtained from UgoBasile (Comerio, VA, Italy).

\subsection{Pj-EE and Preparation of Its Solvent Fractions}

P. japonica was acquired from the Prasiola Japonica Research Center (Samcheok City, Gangwon-do, Republic of Korea) and was extracted as in previous studies $[13,19,20]$. Briefly, pieces of cut samples were extracted with $70 \%$ ethanol for $24 \mathrm{~h}$ at a ratio of 1:20 (w/v). Subsequently, the extract was filtered using $120 \mathrm{~nm}$ filter paper (No. 2, Advantec, Toyo Co., Tokyo, Japan), concentrated using a vacuum concentrator (Eyela New Rotary Vacuum Evaporator, Rikakikai Co., Tokyo, Japan), and then dried using a vacuum freeze dryer (Eyela FD1, Rikakikai Co.). The yield of the dried samples was measured. The final weight of the extract was $29.974 \mathrm{~g}$ (original sample: $210.41 \mathrm{~g}$ ) with a yield of $14.24 \%$. In addition, the ethanolic extract of P. japonica (crude extract) was then fractionated by various polarity solvents including n-hexane (Pj-EE-HF), chloroform (Pj-EE-CF), n-butanol (Pj-EE-BF), and water (Pj-EE-WF) as illustrated in Figure 6. The dried samples were kept in a $-20{ }^{\circ} \mathrm{C}$ freezer for future use. For the in vitro studies, stock solutions of Pj-EE and of its solvent fraction were prepared by dissolving them with DMSO at a concentration of $100 \mathrm{mg} / \mathrm{mL}$. When each experiment was performed, the stock solution was diluted to the desired final concentration of $12.5,25,50,100$, or $200 \mu \mathrm{g} / \mathrm{mL}$ using the suitable culture medium. For the paw edema mouse model experiments, the stock solution was made in $0.5 \% \mathrm{CMC}$ at doses of $100 \mathrm{mg} / \mathrm{kg}$. 


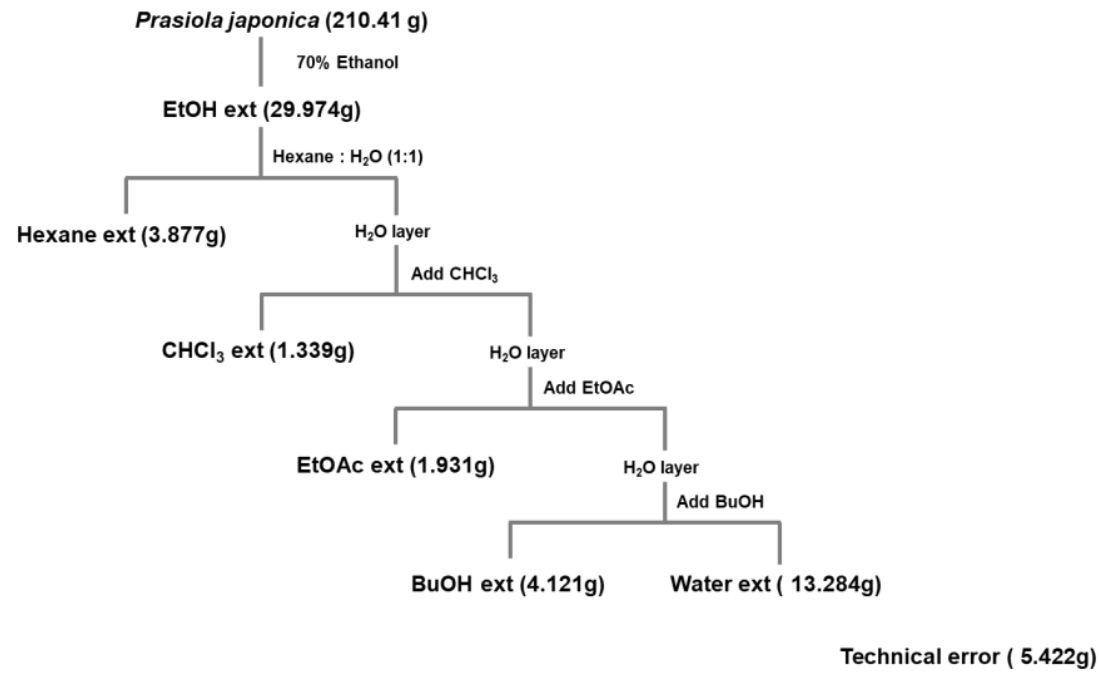

Figure 6. Schematic: preparation of ethanolic extract and four solvent fractions of Prasiola japonica.

\subsection{Cell Culture and Treatment}

The murine macrophage cell line (RAW264.7) and the human embryonic kidney cell line (HEK293) were cultured as previously reported [39]. For a preliminary study, LPSinduced RAW264.7 cells were pretreated at a concentration of $100 \mu \mathrm{g} / \mathrm{mL}$ of Pj-EE and its solvent fractions, whereas for the next experiments, LPS-activated RAW264.7 cells were pretreated with Pj-EE-CF at concentration 12.5, 25, and $50 \mu \mathrm{g} / \mathrm{mL}$. The control (LPS alone) and normal groups were pretreated with diluted DMSO in culture medium for $30 \mathrm{~min}$. The final concentration of DMSO in the cellular experimental conditions was $<0.5 \%$.

\subsection{Determination of NO and Cytokines Production}

RAW264.7 cells $\left(1 \times 10^{6}\right.$ cells $\left./ \mathrm{mL}\right)$ were seeded in a 96-well plate and then pretreated with the specified concentrations of Pj-EE and its solvent fractions for $30 \mathrm{~min}$. LPS $(1 \mu \mathrm{g} / \mathrm{mL})$ was then treated for the next $24 \mathrm{~h}$. The suppression effect of Pj-EE and its solvent fractions on the secretion of $\mathrm{NO}$ was analyzed using Griess reagents, as previously described [40]. The suppression effects of Pj-EE and its solvent fractions on the secretion of IL-1 $\beta$, IL-4, and TNF- $\alpha$ were detected using an EIA kit according to the manufacturer's instructions (R\&D Systems, catalog no. MLB00C, M4000B, and MTA00B, respectively). Briefly, after diluting the supernatant in the indicated assay diluent $1: 1,100 \mu \mathrm{L}$ was added to each well in a 96-well plate coated with anti-mouse IgG. After washing 5 times with wash buffer $(400 \mu \mathrm{L}), 100 \mu \mathrm{L}$ of mouse IL-1 $\beta$, IL-4, or TNF- $\alpha$ conjugate was added to each well and incubated for $2 \mathrm{~h}$. After the reaction and washing, $100 \mu \mathrm{L}$ of substrate solution was added to each well and incubated for an additional $30 \mathrm{~min}$. The incubation was stopped with $100 \mu \mathrm{L}$ of the substrate solution and was measured at $450 \mathrm{~nm}$.

\subsection{Cell Viability Assay}

The cytotoxic effects of Pj-EE and its solvent fractions were determined by a conventional MTT assay as previously reported [41]. We seeded RAW264.7 cells into 96-well plates and preincubated the overnight $(16 \mathrm{~h})$. Afterwards, we treated them with the indicated concentrations of Pj-EE and its solvent fractions or DMSO (for the normal group) for an additional $24 \mathrm{~h}$.

\subsection{Liquid Chromatography-Tandem Mass Spectrometry (LC-MS/MS)}

The phytochemical screening of Pj-EE-CF was characterized by LC-MS/MS. LCMS/MS analyses were performed as previously described [23]. 


\section{7. mRNA Analysis by Quantitative Real-Time Polymerase Chain Reaction ( $q P C R$ )}

Total RNA was obtained from macrophage-like RAW264.7 cells $\left(1 \times 10^{6}\right.$ cells $\left./ \mathrm{mL}\right)$ that were pretreated with Pj-EE-CF $(0,12.5,25$, and $50 \mu \mathrm{g} / \mathrm{mL})$ for $30 \mathrm{~min}$ followed by induction with LPS $(1 \mu \mathrm{g} / \mathrm{mL})$ for $6 \mathrm{~h}$. Paw tissues of mice were ground, and then stored at $-70^{\circ} \mathrm{C}$ until use. Total RNA was prepared using TRIzol per the manufacturer's instructions, and then $1 \mu \mathrm{g}$ of total RNA was immediately made for cDNA synthesis using a cDNA synthesis kit (Thermo Fisher Scientific, Waltham, MA, USA) per the manufacturer's instructions. The qPCR was performed as previously reported [21]. The primer sequences used in this study are listed in Table 1.

Table 1. Primer sequences used for quantitative real-time PCR.

\begin{tabular}{|c|c|c|c|}
\hline PCR Type & Genes Name & & quence $\left(5^{\prime}-3^{\prime}\right)$ \\
\hline \multirow{18}{*}{ q PCR } & \multirow[b]{2}{*}{ GAPDH } & Forward & GAAGGTCGGTGTGAACGGAT \\
\hline & & Reverse & AGTGATGGCATGGACTGTGG \\
\hline & \multirow{2}{*}{ iNOS } & Forward & CAAGAGAACGGAGAACGGAGA \\
\hline & & Reverse & GATGGACCCCAAGCAAGACT \\
\hline & \multirow{2}{*}{ COX-2 } & Forward & TGAGTACCGCAAACGCTTCT \\
\hline & & Reverse & TGGGAGGCACTTGCATTGAT \\
\hline & \multirow{2}{*}{ TNF- $\alpha$} & Forward & TTGACCTCAGCGCTGAGTTG \\
\hline & & Reverse & CCTGTAGCCCACGTCGTAGC \\
\hline & \multirow{2}{*}{ IL-1 $\beta$} & Forward & CAGGATGAGGACATGAGCACC \\
\hline & & Reverse & СТСTGCAGACTCAAACTCСАC \\
\hline & \multirow{2}{*}{ IL-6 } & Forward & GCCTTCTTGGGACTGATGCT \\
\hline & & Reverse & TGGAAATTGGGGTAGGAAGGAC \\
\hline & \multirow{2}{*}{ IL-4 } & Forward & GGTCTCAACCCCCAGCTAGT \\
\hline & & Reverse & GCCCATGATCTCTCTCAAGT \\
\hline & \multirow{2}{*}{ MMP-2 } & Forward & GTCCCTACCGAGTCTCTTCT \\
\hline & & Reverse & TTTTTAAGTTTCCGCTTCTG \\
\hline & \multirow{2}{*}{ MMP-9 } & Forward & GCCACTTGTCGGCGATAAGG \\
\hline & & Reverse & CACTGTCCACСССТCAGAGC \\
\hline
\end{tabular}

\subsection{Luciferase Reporter Gene Assay}

HEK293 cells $\left(2 \times 10^{5}\right.$ cells $\left./ \mathrm{mL}\right)$ were seeded in 24-well plates and preincubated overnight before transfection of plasmids encoding AP-1-Luc under cotransfection conditions with MyD88 and TRIF, by PEI methods as previously reported [23]. After $24 \mathrm{~h}$ transfection, the cells were treated with 12.5, 25 or $50 \mu \mathrm{g} / \mathrm{mL}$ of Pj-EE-CF for an additional $24 \mathrm{~h}$.

\subsection{Cell Lysate Extraction and Immunoblotting Analysis}

RAW264.7 cells $\left(1 \times 10^{6}\right.$ cells $\left./ \mathrm{mL}\right)$ were seeded in a 6-well plate. After pretreatment with different concentrations of PJ-EE-CF for $30 \mathrm{~min}$, LPS was treated and then incubated for the next $24 \mathrm{~h}$. After harvesting and washing with PBS, RAW264.7 cells were lysed in lysis buffer as previously described [42]. Approximately $20 \mu \mathrm{g}$ of protein were subjected to western blot analysis as previously described [23].

\subsection{Animals}

ICR mice (8 weeks old, 20-22 g, male) were purchased from Daehan Biolink (Chung cheonbuk, Korea). The mice ( $n=6$ per group) had water and a pellet diet (Samyang, Daejeon, Korea) ad libitum in separate cages under a $12 \mathrm{~h}$ light-dark cycle. The in vivo experiments were conducted in agreement with the guidelines of the Institutional Animal Care and Use Committee, Sungkyunkwan University (Suwon, Korea; approval ID: SKKUIACUC2020-06-39-1). 


\subsection{Carrageenan-Induced Acute Paw Edema Mouse Model}

Using ICR mice (6 mice/group), paw edema was stimulated by a $100 \mu \mathrm{L}$ subplantar injection of $1 \%$ newly made solution of carrageenan in PBS into both hind paws, as in the previously published report [27]. ICR mice were orally administrated with $100 \mu \mathrm{L}$ of specific solutions for the different groups: normal group $(0.5 \% \mathrm{CMC})$, carrageenan alone as control group (0.5\% CMC), and treatment groups (100 mg/ kg Pj-EE and its solvent fractions) once a day for 10 days. After that, carrageenan-induced paw edema was apparently observed in each group except the normal group (subplantar injection with PBS). After $3 \mathrm{~h}$, the mice were sacrificed by $\mathrm{CO}_{2}$. Subsequently, redness and swelling was observed in both paws. The weight, thickness, and volume of the edema were measured as described previously [20].

\subsection{Statistical Analysis}

All data in this study represent the mean \pm standard deviation of four samples (in vitro experiments). Similar experimental data were obtained from additional independent experiments performed under the same conditions with six mice per group (in vivo experiments). Statistical analyses was performed using the computer program SPSS (version 26, SPSS Inc., Chicago, IL, USA). A comparison of statistical differences of all measured data was subjected to one-way ANOVA followed by the Holm-Sidak test or the KruskalWallis/Mann-Whitney test. A $p$-value of $<0.05$ was considered to be statistically significant.

\section{Conclusions}

The present study, using in vitro and in vivo experiments, clearly indicated and supported the evidence of the anti-inflammatory effects of Pj-EE. Pj-EE-CF showed a particularly potent inhibition of inflammatory responses by targeting ERK and p38, thereby suppressing the activity of AP-1 that could result in attenuation of various inflammatory mediators and cytokines, as summarized in Figure 7. The anti-inflammatory activity of $\mathrm{Pj}$-EE-CF is provided in the context of bioactive molecules that have demonstrated this function in previous studies. In the future, $\mathrm{Pj}$-EE could be a good natural source of an antiinflammatory agent, especially Pj-EE-CF. Further investigations are necessary to evaluate and isolate the bioactive molecules present in Pj-EE-CF.

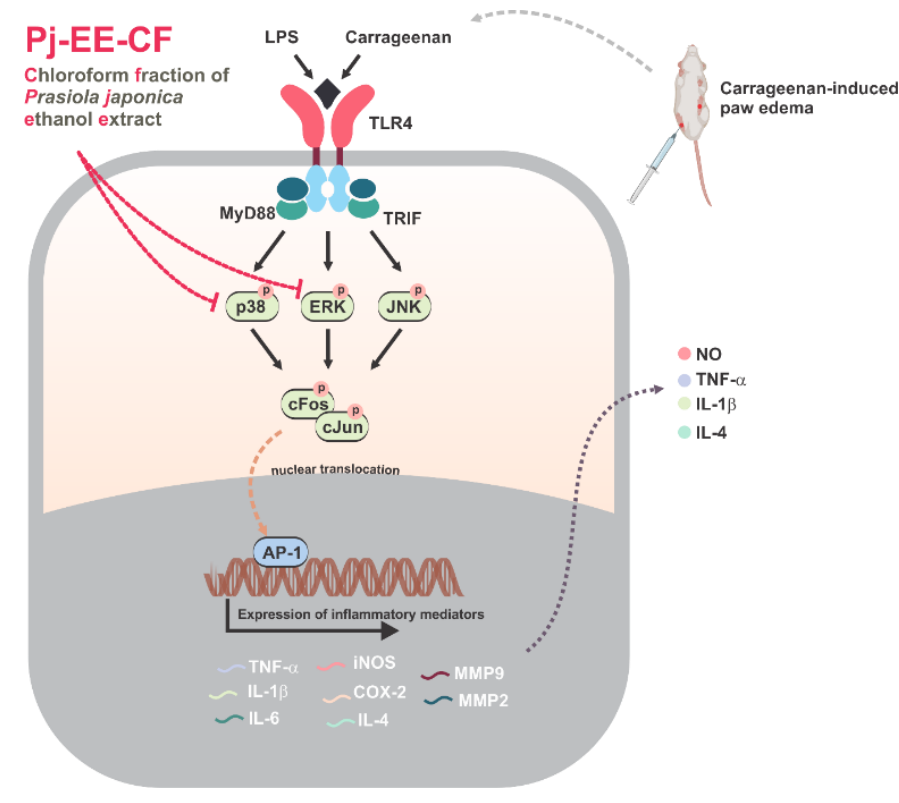

Figure 7. Schematic: anti-inflammatory mechanisms of Pj-EE-CF in the suppression of AP-1 signaling pathway. 


\section{Supplementary Materials: Supplementary Table S1: LC-MS/MS of Pj-EE-CF.}

Author Contributions: S.H.P., D.S.K. (Dong Sam Kim), S.G.J. and J.Y.C.; conceived and designed the experiments; L.R., S.H.P., D.S.K. (Dong Seon Kim), H.P.L., C.Y.L., S.A.K. and J.Y.C. analyzed the data; S.H.P., D.S.K. (Dong Seon Kim), H.P.L., C.Y.L. and S.A.K. performed the experiments; L.R. and N.A. visualized the data; L.R., D.S.K. (Dong Sam Kim) and J.Y.C. wrote the manuscript. All authors have read and agreed to the published version of the manuscript.

Funding: This research was supported by Samcheok Prasiola Japonica Research Center, Samcheok City Hall, Korea.

Institutional Review Board Statement: The in vivo experiments were performed in agreement with the guidelines of the Institutional Animal Care and Use Committee Sungkyunkwan University (Suwon, Korea; approval ID: SKKUIACUC2020-06-39-1)

Informed Consent Statement: Not applicable.

Data Availability Statement: The data used to support the findings of this study are available from the corresponding author upon request.

Acknowledgments: Not applicable.

Conflicts of Interest: The authors have no conflicts of interest to declare.

Sample Availability: Samples of the compound, $\mathrm{Pj}-\mathrm{EE}-\mathrm{CF}$, are available from the authors.

$\begin{array}{ll}\text { Abbreviations } \\ \text { LPS } & \text { Lipopolysaccharide } \\ \text { MyD88 } & \text { Myeloid differentiation factor } 88 \\ \text { AP-1 } & \text { Activator protein-1 } \\ \text { MAPKs } & \text { Mitogen-activated protein kinases } \\ \text { JNK } & \text { c-Jun N-terminal kinase } \\ \text { RPMI 1640 } & \text { Roswell Park Memorial Institute 1640 } \\ \text { DMEM } & \text { Dulbecco's modified Eagle's medium } \\ \text { COX-2 } & \text { Cyclooxygenase-2 } \\ \text { MMP } & \text { Matrix metalloproteinase } \\ \text { IL-1 } \beta & \text { Interleukin-1 } \beta \\ \text { IL-6 } & \text { Interleukin 6 } \\ \text { TNF- } \alpha & \text { Tumor necrosis factor alpha } \\ \text { MKK } & \text { Mitogen-activated protein kinase } \\ \text { iNOS } & \text { Inducible nitric oxide synthase }\end{array}$

\section{References}

1. Kumar, H.; Kawai, T.; Akira, S. Pathogen recognition by the innate immune system. Int. Rev. Immunol. 2011, 30, 16-34. [CrossRef] [PubMed]

2. Mogensen, T.H. Pathogen recognition and inflammatory signaling in innate immune defenses. Clin. Microbiol. Rev. 2009, 22, 240-273. [CrossRef]

3. Chen, L.; Deng, H.; Cui, H.; Fang, J.; Zuo, Z.; Deng, J.; Li, Y.; Wang, X.; Zhao, L. Inflammatory responses and inflammationassociated diseases in organs. Oncotarget 2017, 9, 7204-7218. [CrossRef] [PubMed]

4. Janssens, S.; Beyaert, R. Role of toll-like receptors in pathogen recognition. Clin. Microbiol. Rev. 2003, 16, 637-646. [CrossRef]

5. Kuzmich, N.N.; Sivak, K.V.; Chubarev, V.N.; Porozov, Y.B.; Savateeva-Lyubimova, T.N.; Peri, F. TLR4 signaling pathway modulators as potential therapeutics in inflammation and sepsis. Vaccines 2017, 5, 34. [CrossRef]

6. $\quad$ Lopes, A.H.; Silva, R.L.; Fonseca, M.D.; Gomes, F.I.; Maganin, A.G.; Ribeiro, L.S.; Marques, L.M.M.; Cunha, F.Q.; Alves-Filho, J.C.; Zamboni, D.S.; et al. Molecular basis of carrageenan-induced cytokines production in macrophages. Cell Commun. Signal. 2020, 18, 141. [CrossRef]

7. Yang, Y.; Kim, S.C.; Yu, T.; Yi, Y.S.; Rhee, M.H.; Sung, G.H.; Yoo, B.C.; Cho, J.Y. Functional roles of p38 mitogen-activated protein kinase in macrophage-mediated inflammatory responses. Mediat. Inflamm. 2014, 2014, 352371. [CrossRef] [PubMed]

8. Aktan, F. iNOS-mediated nitric oxide production and its regulation. Life Sci. 2004, 75, 639-653. [CrossRef]

9. Cheng, G.; Wei, L.; Xiurong, W.; Xiangzhen, L.; Shiguang, Z.; Songbin, F. IL-17 stimulates migration of carotid artery vascular smooth muscle cells in an MMP-9 dependent manner via p38 MAPK and ERK1/2-dependent NF-kappaB and AP-1 activation. Cell. Mol. Neurobiol. 2009, 29, 1161-1168. [CrossRef] 
10. Dinarello, C.A. Proinflammatory cytokines. Chest 2000, 118, 503-508. [CrossRef]

11. Manicone, A.M.; McGuire, J.K. Matrix metalloproteinases as modulators of inflammation. Semin. Cell Dev. Biol. 2008, 19, 34-41. [CrossRef]

12. Chen, S.; Guo, J.; Feng, C.; Ke, Z.; Chen, L.; Pan, Y. The preoperative platelet-lymphocyte ratio versus neutrophil-lymphocyte ratio: Which is better as a prognostic factor in oral squamous cell carcinoma? Ther. Adv. Med. Oncol. 2016, 8, 160-167. [CrossRef]

13. Park, S.H.; Choi, E.; Kim, S.; Kim, D.S.; Kim, J.H.; Chang, S.; Choi, J.S.; Park, K.J.; Roh, K.B.; Lee, J.; et al. Oxidative stress-protective and anti-melanogenic effects of loliolide and ethanol extract from fresh water green algae, Prasiola japonica. Int. J. Mol. Sci. 2018, 19, 2825. [CrossRef]

14. Saini, D.K.; Pabbi, S.; Shukla, P. Cyanobacterial pigments: Perspectives and biotechnological approaches. Food Chem. Toxicol. 2018, 120, 616-624. [CrossRef] [PubMed]

15. Drew, K.M.; Friedmann, I. Occurrence of motile gametes in Prasiola stipitata Suhr. Nature 1957, 180, 557-558. [CrossRef]

16. Morphology and phylogenetic position of a freshwater Prasiola species (Prasiolales, Chlorophyta) in Korea. Algae 2015, 30, 197-205. [CrossRef]

17. Naw, M.W.D.; Hara, Y. Morphology and molecular phylogeny of Prasiola sp. (Prasiolales, Chlorophyta) from Myanmar. Phycol. Res. 2002, 50, 175-182. [CrossRef]

18. Da Woom, S.; Hee Jung, K.; Su Kil, J.; Mansig, J.; Seong Soo, J. Screening of functional components derived from fresh water laver, Prasiola japonica, and its pharmacological properties. J. Biomed. Res. 2013, 14, 83-90.

19. Choi, E.; Yi, Y.-S.; Lee, J.; Park, S.H.; Kim, S.; Hossain, M.A.; Jang, S.; Choi, Y.I.; Park, K.J.; Kim, D.S.; et al. Anti-apoptotic and anti-inflammatory activities of edible fresh water algae Prasiola japonica in UVB-irradiated skin keratinocytes. Am. J. Chin. Med. 2019, 47, 1853-1868. [CrossRef] [PubMed]

20. Lee, C.Y.; Park, S.H.; Lim, H.Y.; Jang, S.G.; Park, K.J.; Kim, D.S.; Kim, J.H.; Cho, J.Y. In vivo anti-inflammatory effects of Prasiola japonica ethanol extract. J. Funct. Foods 2021, 80, 104440. [CrossRef]

21. Aziz, N.; Son, Y.J.; Cho, J.Y. Thymoquinone suppresses IRF-3-mediated expression of Type I interferons via suppression of TBK1. Int. J. Mol. Sci. 2018, 19, 1355. [CrossRef]

22. Kim, H.P.; Son, K.H.; Chang, H.W.; Kang, S.S. Anti-inflammatory plant flavonoids and cellular action mechanisms. J. Pharmacol. Sci. 2004, 96, 229-245. [CrossRef] [PubMed]

23. Rahmawati, L.; Aziz, N.; Oh, J.; Hong, Y.H.; Woo, B.Y.; Hong, Y.D.; Manilack, P.; Souladeth, P.; Jung, J.H.; Lee, W.S.; et al Cissus subtetragona Planch. ameliorates inflammatory responses in LPS-induced macrophages, $\mathrm{HCl} / \mathrm{EtOH}$-induced fastritis, and LPS-induced lung injury via attenuation of Src and TAK1. Molecules 2021, 26, 6073. [CrossRef]

24. Park, B.S.; Lee, J.-O. Recognition of lipopolysaccharide pattern by TLR4 complexes. Exp. Mol. Med. 2013, 45, e66. [CrossRef] [PubMed]

25. Yi, Y.-S.; Cho, J.Y.; Kim, D. Cerbera manghas methanol extract exerts anti-inflammatory activity by targeting c-Jun N-terminal kinase in the AP-1 pathway. J. Ethnopharmacol. 2016, 193, 387-396. [CrossRef] [PubMed]

26. Mansouri, M.T.; Hemmati, A.A.; Naghizadeh, B.; Mard, S.A.; Rezaie, A.; Ghorbanzadeh, B. A study of the mechanisms underlying the anti-inflammatory effect of ellagic acid in carrageenan-induced paw edema in rats. Indian J. Pharmacol. 2015, 47, 292-298. [CrossRef]

27. Winter, C.A.; Risley, E.A.; Nuss, G.W. Carrageenin-induced edema in hind paw of the rat as an assay for antiiflammatory drugs. Proc. Soc. Exp. Biol. Med. Soc. Exp. Biol. Med. 1962, 111, 544-547. [CrossRef] [PubMed]

28. Zhao, J.; Maitituersun, A.; Li, C.; Li, Q.; Xu, F.; Liu, T. Evaluation on analgesic and anti-inflammatory activities of total flavonoids from Juniperus sabina. Evid. -Based Complementary Altern. Med. Ecam 2018, 2018, 7965306. [CrossRef]

29. Hämäläinen, M.; Nieminen, R.; Vuorela, P.; Heinonen, M.; Moilanen, E. Anti-inflammatory effects of flavonoids: Genistein, kaempferol, quercetin, and daidzein inhibit STAT-1 and NF-kappaB activations, whereas flavone, isorhamnetin, naringenin, and pelargonidin inhibit only NF-kappaB activation along with their inhibitory effect on iNOS expression and NO production in activated macrophages. Mediat. Inflamm. 2007, 2007, 45673. [CrossRef]

30. Kim, S.H.; Park, J.G.; Lee, J.; Yang, W.S.; Park, G.W.; Kim, H.G.; Yi, Y.S.; Baek, K.S.; Sung, N.Y.; Hossen, M.J.; et al. The dietary flavonoid kaempferol mediates anti-inflammatory responses via the Src, Syk, IRAK1, and IRAK4 molecular targets. Mediat. Inflamm. 2015, 2015, 904142. [CrossRef]

31. Survay, N.S.; Upadhyaya, C.P.; Kumar, B.; Young, K.E.; Yoon, D.-Y.; Park, S.-W. New genera of flavonols and flavonol derivatives as therapeutic molecules. J. Korean Soc. Appl. Biol. Chem. 2011, 54, 1-18. [CrossRef]

32. Park, I.; Goo, D.; Nam, H.; Wickramasuriya, S.S.; Lee, K.; Zimmerman, N.P.; Smith, A.H.; Rehberger, T.G.; Lillehoj, H.S. Effects of dietary maltol on innate immunity, gut health, and growth performance of broiler chickens challenged with Eimeria maxima. Front. Vet. Sci. 2021, 8, 508. [CrossRef]

33. Liao, W.; Liu, Z.; Zhang, T.; Sun, S.; Ye, J.; Li, Z.; Mao, L.; Ren, J. Enhancement of anti-inflammatory properties of nobiletin in macrophages by a nano-emulsion preparation. J. Agric. Food Chem. 2018, 66, 91-98. [CrossRef]

34. Jeong, J.W.; Lee, H.H.; Han, M.H.; Kim, G.Y.; Kim, W.J.; Choi, Y.H. Anti-inflammatory effects of genistein via suppression of the toll-like receptor 4-mediated signaling pathway in lipopolysaccharide-stimulated BV2 microglia. Chem. -Biol. Interact. 2014, 212, 30-39. [CrossRef] 
35. Wang, Z.; Hao, W.; Hu, J.; Mi, X.; Han, Y.; Ren, S.; Jiang, S.; Wang, Y.; Li, X.; Li, W. Maltol improves APAP-induced hepatotoxicity by inhibiting oxidative stress and inflammation response via NF-KB and PI3K/Akt signal pathways. Antioxidants 2019, 8, 395. [CrossRef] [PubMed]

36. Kang, X.; Jin, D.; Zhang, Y.; Zhou, R.; Zhang, Y.; Lian, F. Systematic elucidation of the mechanism of Sappan lignum in the treatment of diabetic peripheral neuropathy based on network pharmacology. Evid. -Based Complementary Altern. Med. 2021, 2021, 5528018. [CrossRef] [PubMed]

37. Anand, K.K.; Sharma, M.L.; Singh, B.; Ghatak, B.J. Antiinflamatory, antipyretic \& analgesic properties of bavachinin-a flavanone isolated from seeds of Psoralea corylifolia Linn. (Babchi). Indian J. Exp. Biol. 1978, 16, 1216-1217.

38. Zeng, K.W.; Yu, Q.; Song, F.J.; Liao, L.X.; Zhao, M.B.; Dong, X.; Jiang, Y.; Tu, P.F. Deoxysappanone B, a homoisoflavone from the Chinese medicinal plant Caesalpinia sappan L., protects neurons from microglia-mediated inflammatory injuries via inhibition of IкB kinase (IKK)-NF-кB and p38/ERK MAPK pathways. Eur. J. Pharm. 2015, 748, 18-29. [CrossRef] [PubMed]

39. Kim, H.G.; Kim, M.Y.; Cho, J.Y. Alisma canaliculatum ethanol extract suppresses inflammatory responses in LPS-stimulated macrophages, $\mathrm{HCl} / \mathrm{EtOH}$-induced gastritis, and DSS-triggered colitis by targeting Src/Syk and TAK1 activities. J. Ethnopharmacol. 2018, 219, 202-212. [CrossRef]

40. Misko, T.P.; Schilling, R.J.; Salvemini, D.; Moore, W.M.; Currie, M.G. A Fluorometric assay for the measurement of nitrite in biological samples. Anal. Biochem. 1993, 214, 11-16. [CrossRef]

41. Gerlier, D.; Thomasset, N. Use of MTT colorimetric assay to measure cell activation. J. Immunol. Methods 1986, $94,57-63$. [CrossRef]

42. Hong, Y.H.; Kim, J.H.; Cho, J.Y. Ranunculus bulumei methanol extract exerts anti-inflammatory activity by targeting Src/Syk in NF-kB signaling. Biomolecules 2020, 10, 546. [CrossRef] [PubMed] 